\title{
$O$ ideal social da escola doméstica/RN - relatos de uma memória
}

\author{
The social ideal of the domestic school/RN - reports from a memory \\ El ideal social de la escuela doméstica/RN - informes de una memoria
}

Recebido: 15/09/2021 | Revisado: 20/09/2021 | Aceito: 23/09/2021 | Publicado: 24/09/2021

\author{
Vanessa Souza de Miranda \\ ORCID: https://orcid.org/0000-0002-4411-8217 \\ Universidade Federal do Rio Grande do Norte, Brasil \\ E-mail: miranda.vanessa@outlook.com \\ Kilza Fernanda Moreira de Viveiros \\ ORCID: https://orcid.org/0000-0003-1243-7595 \\ Universidade Federal do Rio Grande do Norte, Brasil \\ E-mail: kilza.fernanda@hotmail.com
}

\begin{abstract}
Resumo
O presente trabalho discorre sobre a fundação da Escola Doméstica de Natal/RN e comprova o modelo de escola feminina a começar do estudo da Puericultura. Objetivando analisar a trajetória da escola citada, pretendendo compreender o percurso até a sua fundação (1914) e os avanços que trouxeram contribuições nos campos social, intelectual e tecnológico analizados após sua inserção na capital Potiguar. Nosso trabalho ampara-se por sua importância enquanto instituição Escola Doméstica para a sociedade natalense. Por ser referência para as instituições de ensino feminino no Brasil, pois os ensinamentos promoveram um enfoque diferenciado ao currículo, ao proporcionar uma educação moderna e culta as alunas. Com aprendizados direcionados para a sua saúde, ao propiciar o cuidado e crescimento saudável das crianças por meio do estudo da puericultura. Essa pesquisa desenvolve-se no âmbito da História Cultural fundamentada teórico-metodologicamente por meio de fontes documentais e bibliográficas sobre a Escola Doméstica de Natal. Apoiada nos conceitos de Memória; Modernização; Puericultura; Educação Feminina; Contexto Social, Cultural, Histórico e Político apontando a época analisada. Concluímos que a vontade em oportunizar uma educação moderna e de formação científica com conhecimentos teóricos e práticos necessários para a educação das jovens moças do Estado do Rio Grande do Norte, foi um marco para a educação feminina.
\end{abstract}

Palavras-chave: Escola doméstica; Educação feminina; Puericultura; Memória; Modernização.

\begin{abstract}
The present work discusses the foundation of the Domestic School of Natal/RN and proves the model of the feminine school starting from the study of Childcare. Aiming to analyze the trajectory of the mentioned school, intending to understand the path to its foundation (1914) and the advances that brought contributions in the social, intellectual and technological fields analyzed after its insertion in the Potiguar capital. Our work is supported by its importance as a Domestic School institution for Natal society. For being a reference for institutions of female education in Brazil, as the teachings promoted a differentiated focus on the curriculum, by providing a modern and cultured education to the students. With learning aimed at their health, by providing care and healthy growth of children through the study of childcare. This research is developed within the scope of Cultural History, theoretically-methodologically grounded through documentary and bibliographic sources about the Domestic School of Natal. Supported by the concepts of Memory; Modernization; Childcare; Women's Education; Social, Cultural, Historical and Political Context pointing to the analyzed period. We conclude that the desire to provide a modern education and scientific training with theoretical and practical knowledge necessary for the education of young girls in the State of Rio Grande do Norte, was a milestone for female education.
\end{abstract}

Keywords: Domestic school; Women's education; Childcare; Memory; Modernization.

\section{Resumen}

El presente trabajo discute la fundación de la Escuela Doméstica de Natal / RN y prueba el modelo de escuela femenina a partir del estudio de la puericultura. Con el objetivo de analizar la trayectoria de la mencionada escuela, con la intención de comprender el camino hacia su fundación (1914) y los avances que trajeron aportes en los campos social, intelectual y tecnológico analizados luego de su inserción en la capital Potiguar. Nuestro trabajo se sustenta en su importancia como institución de Escuela Doméstica para la sociedad natal. Por ser una referencia para las instituciones de educación femenina en Brasil, ya que las enseñanzas promovieron un enfoque diferenciado en el currículo, al brindar una educación moderna y culta a los estudiantes. Con aprendizajes orientados a su salud, brindando cuidados y crecimiento saludable a los niños a través del estudio de la puericultura. Esta investigación se desarrolla en el ámbito de la Historia Cultural, fundamentada teórica-metodológicamente a través de fuentes 
documentales y bibliográficas sobre la Escuela Doméstica de Natal. Apoyado en los conceptos de Memoria; Modernización; Cuidado de niños; Educación de la mujer; Contexto social, cultural, histórico y político que apunta al período analizado. Concluimos que el deseo de brindar una educación moderna y una formación científica con los conocimientos teóricos y prácticos necesarios para la educación de las niñas en el Estado de Rio Grande do Norte, fue un hito para la educación femenina.

Palabras clave: Escuela doméstica; Educación de la mujer; Cuidado de niños; Memoria; Modernización.

\section{Introdução}

O presente trabalho discorre sobre a fundação da Escola Doméstica de Natal/RN e comprova o modelo de escola feminina a começar do estudo da Puericultura. Objetivando analisar a trajetória da escola citada, pretendendo compreender o percurso até a sua fundação (1914) e os avanços que trouxeram contribuições nos campos social, intelectual e tecnológico analizados após sua inserção na capital Potiguar.

Identificando a importância de uma educação voltada para a mulher, no âmbito da Escola Doméstica de Natal, foi que despontou a recomendação para a instituição de uma escola com ensinamento inovador que concebia uma instrução moderna e direcionava à idealização de uma nova representação de mulher que se dedicaria aos ensinamentos adequados da formação do vínculo familiar, conforme afirma Miranda (2021, p. 17, no prelo), é um "novo perfil de mulher, um modelo civilizado em meio a uma sociedade na qual se apontavam", "os primeiros indícios de desenvolvimento social e econômico", reitera Rodrigues (2007, p.83). As autoridades públicas do estado do Rio Grande do Norte mantiveram um clima de orgulho e esperança por ser possível promover avanços reais para a capital potiguar.

Em Natal, a modernização chegou a passos lentos, e isso era revelado pelo modelo atrasado de sociedade, ao observar outras capitais do Brasil. Rodrigues (2007, p. 88) afirma que a vida dos natalenses era bastante precária quando se referia a modernidade. Os cidadãos tiveram acesso as primeiras instalações elétricas a partir dos anos de 1905. Foi na gestão do governador Alberto Maranhão que outros benefícios foram sendo proporcionado para a população, como por exemplo a distribuição de água, saneamento, transporte, calçamento [...].

Entende-se como necessário um novo ordenamento político-cultural nacional, com a implantação de um universo cognitivo modernizante que, em última instância, no projeto republicano libertaria o Brasil de seus resquícios rurais e coloniais. Uma das estratégias adotadas pelo Estado foi a reformulação do espaço urbano no início do século XX [...]. Em 1908, no governo de Alberto Albuquerque Maranhão, o crescimento demográfico demandava urbanização, higienização e disciplinamento da cidade (Pinheiro, 2005, p. 74).

Para Pinheiro (2005, p. 74) citado por Miranda (2021, p. 18, no prelo), esses acontecimentos ficaram marcados como um avanço, diante dos norte-rio-grandense, além de esclarecer que as melhorias implantadas podiam ser benéficas para o desenvolvimento da cidade, a sociedade agia com muita resistência no que diz respeito a aceitar os projetos propostos. Porém, por desejarem alcançar a modernização que outras cidades do Brasil já estavam usufruindo, a sociedade entendeu que era urgente e foi concordando com a estruturação proposta, principalmente porque essas mudanças lhes trariam benefícios, principalmente para os homens da alta sociedade, os políticos, fazendeiros, médicos, por exemplo.

Modernização, conforme Pinheiro (2005, p. 67) defende, é um “processo de fluxo contínuo, no qual não há diferenciação real de uma conjuntura ou época em relação à outra, a não ser pela sucessão cronológica ou novo se convertendo em velho, o anterior em posterior, e assim sucessivamente".

"As nações atingidas pelo imperialismo ocidental, quando conseguiram alcançar mais ou menos sua independência, foram confrontadas com o problema do seu atraso em certos campos”, Le Goff (1990, p. 163) esclarece a questão da modernização afirmando que ela foi também emblemática para os indivíduos que vivenciaram mudanças em seu meio, embora considerassem que essas transformações era de fato a mudança do que rememorava o passado, que por vezes indicava atraso, 
para o que havia de mais atual para a sociedade à época.

Dentre as muitas problemáticas surgidas nos processos de modernização, Miranda (2021, p. 18, no prelo) nos afirma que muitas vezes não se preservavam os valores que foram construídos na formação da identidade desse povo, revelando o apagamento de práticas culturais e modelos estruturais que um dia caracterizou aquele povo.

Viver em uma cidade tranquila tinha suas benfeitorias, no entanto era necessário perceber a importancia de modernizar para o seu crescimento, somente os bairros da elite que tinham privilégios como energia elétrica, conforme citado anteriormente. No ano da inauguração da Escola Doméstica, 1914, havia aproximadamente "vinte mil habitantes, distribuídos nos bairros de Belo Monte, Cidade Alta, Baldo, Barro Vermelho, Lagoa Seca e Alecrim, sendo a Ribeira o coração da cidade”. Belo Monte, hoje é conhecido por Petrópolis. Escolas ${ }^{1}$ católicas já funcionavam nessa época, e as escolas eram divididas por gêneros, as administradas pelos padres era com ensinamentos voltados para os meninos, e as administradas pelas freiras os ensinamentos eram apenas para as meninas.

Haviam influências sendo copiadas pelos potiguares, como por exemplo a moda, arquitetura, e etc, Barros relata ainda que a sociedade norte-rio-grandense além das tradições da sociedade potiguar foram relatados por Barros (2000). No início do século XX a cidade teve inaugurado o Theatro Carlos Gomes, atual Teatro Alberto Maranhão. Os principais jornais do Estado eram: "A República" e "O Liberal do Norte". O único Hospital era o Hospital de Caridade Juvino Barreto, que atendia todo o RN, hoje conhecido como Hospital Universitário Onofre Lopes.

Somente por meio da educação que a sociedade poderia alcançar o desenvolvimento desejado. A aceitação ao modelo de educação moderna apresentada traria um novo conceito educacional para Natal, no entanto, era necessário que houvesse uma aceitação e também uma ruptura com o passado, buscando novas adequações e entendendo que era necessário disciplinar os pobres também. Esse modelo de educação a ser seguido estava entre os objetivos, principalmente após relatos de Henrique Castriciano quando conheceu a escola suíça,

Ao penetrar a Escola Normal Ménagère de Friburgo senti logo o encanto, o bem-estar que dá a Suíça, em que, não raro, a decoração vegetal imprime uma nota pacificante de bucolismo, dando ao espírito do hóspede um como aviso de tranquilidade, de trabalho silencioso, de ternura forte. (Souza, 1911, p. 29 citado por Rodrigues, 2007, p.19).

Rodrigues (2007, p. 19), descreve ainda que "o espaço físico, o currículo e o funcionamento da escola, os ares de tranquilidade, cultura e ciência despertou em Henrique Castriciano o desejo em divulgar" em Natal e posteriormente por todo o Rio Grande do Norte esse padrão de educação feminina da Suíça.

A educação no Brasil passava, esperava-se que fosse impulsionado o novo modelo de educação que auxiliasse a formação de mulheres mais centradas e que através da educação que eles recebessem estariam aptas a instruir futuros cidadãos interessados no desenvolvimento da sociedade, e que fosse fundamentada aos aspectos de uma escola moderna nos âmbitos social, econômico e cultural. Ao refletir sobre o ideal de educação, Castriciano compreendeu que essa abordagem com aspectos de modernidade traria consigo um modelo de educação feminina aos moldes europeus, foi necessário convencer autoridades para o novo modelo escolar.

Ao observar o empenho das autoridades à época para concretização do projeto Escola Doméstica, Rodrigues (2007, p.98) descreve sobre faltava professores e material para ministrar as aulas nas escolas públicas, a estrutura física das escolas estavam

\footnotetext{
${ }^{1}$ O Colégio Imaculada Conceição das Irmãs Dorotéia, o Ginásio Diocesano Santo Antônio - hoje Colégio Marista, a Escola Normal, o Atheneu, os grupos Escolares Frei Miguelinho e Augusto Severo, e poucas outras escolas, formavam o complexo educacional da cidade (Barros, 2000. p. 83).
} 
desgastadas. Considerar que seria inaugurada em Natal uma escola com ares de modernidade e tendo o apoio dos políticos era descartar os problemas já enfrentados pelo sistema educacional.

Ao lado de "Francisco de S. Meira e Sá, José Augusto Bezerra de Medeiros, entre outros [...]” (Rodrigues, 2007, p. 54), fundaram a Liga de Ensino do Rio Grande do Norte - LERN, “que visava auxiliar os poderes públicos estaduais, em tudo o que dissesse respeito à instrução e à educação do povo" (Barros, 2000, p. 41).

Corroborando com Rodrigues (2007, p. 55),

A fundação da Liga de Ensino do RN - LERN ocorreu em um contexto nacional modelado pela propaganda e retórica do Civismo, um movimento educacional, representado por associações congregadoras de homens de elite, esclarecidos e bem intencionados, devotados à causa social e principalmente educacional. Nessa conjuntura de efervescência voltada para a defesa da nacionalidade, discursos são incorporados às Ligas e proferindo a ausência no país de uma educação mais científica, moderna e democrática, tomando-se como espelho os países mais avançados econômica e socialmente, sem perder de vista os parâmetros da tradição e costume local.

O projeto tinha muita inovação e um currículo arrojado, mesmo contemplando uma educação acessível, a escola se tornou em um ambiente adequado para as moças da elite potiguar. Miranda (2021, p. 20, no prelo) relata sobre o perfil das alunas que frequentavam aquele ambiente escolar, muitas delas eram filhas dos políticos, fazendeiros e pessoas influentes no Estado do Rio Grande do Norte. Investir no currículo, a seleção do corpo docente, o pré-requisito para ingressar na escola e as instruções voltadas para a educação das moças deixou a escola num espaço privilegiado, ao manter o padrão e renovar sempre que necessário.

A escola doméstica tornou-se referência para as escolas de todo Brasil no que se refere a inovação da educação feminina. Sendo marco na representação de modernidade na educação. Após a sua inauguração, a Escola Doméstica "iniciou seu ano letivo com onze alunas. Ainda era o começo, a interrogação, a surpresa. A Liga de Ensino, esforça-se para divulgar o programa da Escola, em conversas, visitas e palestras" (Barros, 2000, p. 105).

O seguinte, em 1915, a convite de Henrique Castriciano, presidente da Liga de Ensino do Rio Grande do Norte, o Dr. Varela Santiago passou a compor o corpo docente da instituição de ensino, trazendo seus conhecimentos acadêmicos para a formação das jovens moças que frequentavam a escola. Inicialmente ele ministrava aulas para as disciplinas de Higiene e Anatomia[...]. Segundo Galvão (2017, p. 80), o jornal "A República”, noticiou em 1916 estava "empenhado em incrementar o curso de Puericultura na Escola Doméstica", ao compartilhar essa intenção com os membros da LERN, e que era necessário construir um pavilhão adequado para ministrar as aulas, foi proposto que se iniciasse uma série de conferências, em prol de arrecadar recursos financeiros para a construção do prédio.

No ano de 1919 foi inaugurado o Instituto de Puericultura, o prédio foi construído seguindo as orientações do Dr. Varela Santiago juntamente com a equipe que projetou, no que diz respeito a qualidade do material, passando a funcionar no prédio anexo a escola, e sendo considerado o primeiro curso de puericultura instalado no RN e em um ambiente escolar. Esse espaço destinado ao acolhimento de crianças funcionava como um laboratório para as aulas de Puericultura, abrangendo em seu programa toda a vida da criança [...] (Mendes \& Menezes, 2011, p. 20).

Galvão (2017, p. 104), relata que

O curso tinha, em seu conteúdo, "o planejamento de aulas voltadas ao bem-estar físico, emocional e psicológico das crianças, as quais eram oriundas, na sua maioria, de famílias de baixa renda" (Galvão, 2017, p. 104) e residentes em Natal ou cidades circunvizinhas. Durante o ano letivo, as crianças ficaram por seis meses "internadas" na casa, sob os cuidados das alunas da Escola Doméstica.

O marco da educação escolar, num ambiente de ensino básico foi trazer para a escola, um espaço de interação e trocas 
sociais ensinamentos distintos das primeiras letras, das matemáticas e do civismo e amor a pátria. O projeto escolar proposto pela Liga de Ensino era inovador e trouxe grandes benefícios para a conduta escolar em nossa sociedade.

Diante do que foi exposto, questiona-se, então, "Qual foi a contribuição que a criação do instituto de Puericultura trouxe para a formação científica e prática das alunas da Escola Doméstica tendo em vista o ideal de escola moderna para a sociedade da época?".

\section{Metodologia}

A modernização trazida por Pinheiro (2005) em sua obra intitulada "Educação e Modernização em Henrique Castriciano", faz um recorte histórico no tocante à educação que Henrique Castriciano tanto almejava. Nela é descrita a relação de encantamento que ele teve ao visitar a École Ménagères, de Friburgo, na Suíça, e também com o modelo social vivenciando pelos europeus, com ares de modernidade, algo não visto pelos potiguares.

Rodrigues (2007) descreve em sua tese "Educar para o lar, educar para a vida: cultura escolar e modernidade educacional na Escola Doméstica de Natal (1914 - 1945)", o olhar diferenciada que constituiu a instituição escolar, ao representar a pluralidade descritas no contexto das práticas educativas e na formulação do currículo da escola, além de nos apresentar os conceitos de memória e cultura escolar que estavam inseridos na escola.

Os autores e pesquisadores o historiador Cláudio Galvão e a Dra. Maria Zélia Fernandes, discorrem sobre a História de vida do Dr. Varela Santiago, médico higienista e professor dedicado a formação de suas alunas, destacando sua trajetória de filantropia visando promover ensinamentos sobre o cuidado com a saúde principalmente dos pequenos.

Nosso referencial tem sido marcado pelas fortes influências de Saviani (2005), Gondra (2000), Julia (2001) e Silva (2013), por exemplo. Os conceitos apresentados por eles nos deram direcionamento para a elaboração dessa pesquisa, e nos possibilitou adquirir a compreensão desejada para pensar sobre as mudanças que a sociedade passava à época da inauguração da escola doméstica, além de nos conduzir ao entendimento de como a sociedade pensava a infância no início do século XX, e o como se comportava o movimento de higiene.

\section{Resultados e Discussão}

\subsection{Rememorando a História}

No dia primeiro de setembro de ano de 1914 inaugurava-se em Natal a Escola Doméstica, idealizada por Henrique Castriciano $^{2}$ de Souza, e com apoio da Liga de Ensino do Rio Grande do Norte (LERN), teve suas portas abertas para os principais representantes da sociedade natalense. Sua sede era própria, situava-se na Praça Augusto Severo, $\mathrm{n}^{\circ}$ 281, tendo por vizinhos a Escola Normal e o Theatro Carlos Gomes, conforme relata Barros (2000, p. 90). A arquitetura à época recebia influências europeias, Rodrigues (2007, p. 254) descreve que

A construção tinha que se pensar num modelo de estrutura física que vislumbrasse os anseios e o projeto de quem a idealizava. A imagem da fachada principal da Escola Doméstica de Natal com traços neoclássicos, visualizada na época em que fora fundada, nos transmite ares de poder e pujança, com típica arquitetura ensejada pelos republicanos no Brasil que almejavam construir no cenário nacional estruturas arquitetônicas com ares de modernidade e progresso, exemplos materializados na construção dos primeiros grupos escolares.

\footnotetext{
${ }^{2}$ Natural do município de Macaíba/RN, nasceu em 15 de março de 1874 e faleceu em Natal/RN, no dia 26 de julho de 1947. Filho de Eloi Castriciano de Souza e Henriqueta Leopoldina Rodrigues, da tradicional elite agrária de Macaíba/RN.
} 
A localização da escola era no Bairro da Ribeira, o mais frequentado pela elite potiguar. Miranda (2021, p. 23, no prelo) aduz que Sua estrutura física atendia aos critérios de acolhimento, e os agentes envolvidos na sua construção foram criando marcas sociais na cultura de uma cidade que, por hora estava querendo evoluir e mostrar sua modernização. Natal tinha uma população de aproximadamente 25 mil habitantes, sendo, a Cidade Alta e a Ribeira, ${ }^{3}$ os bairros mais populosos, no ano de 1914.

O pioneirismo do Estado do Rio Grande do Norte marcou a sua história com a execução " do projeto, como pela contribuição inexcedível que o estabelecimento tem proporcionado [...], na sua área específica de atuação" comenta Lima. ${ }^{4}$ É sabido que muitas mulheres "das famílias mais abastadas viviam em seus casarões, rodeadas de empregados e recebiam uma educação mais recatada, já os homens tinham acesso aos estudos formando-se muitas vezes em cursos de engenharia, direito e medicina". (Miranda, 2021, p.24, no prelo).

Na Europa, a educação feminina soava com ares de modernidade. Barros (2000, p. 89) afirma que na "Suíça, país onde a educação da mulher era encarada com seriedade, trabalhar e atuar eram exercícios de cidadania". Além disso, "na École Ménagère de Friburgo, estudava-se a ciência da dona de casa [...], havia também uma admirável cultura e a profunda intuição da mudança do mundo, através da educação da mulher". A expansão por cursos voltados para a educação doméstica crescia gradativamente no século passado (séc. XX), a pretendia corroborar com "o papel a ser desempenhado pela figura feminina no âmbito familiar e no contexto social”. (Miranda, 2021, p. 24, no prelo).

Rodrigues (2007, p. 84), confirma que a Escola Doméstica não foi pensada para a classe popular, exatamente por ter característica seletiva e elitista. Algumas exigências como cobrança de mensalidade era um fator predominante para definir quem podia ou não frequentar aquele ambiente escolar. Foi nesse contexto que a modernização dentro da educação feminina alcançou as jovens moças do RN. E isso só foi possível graças ao esforço de Henrique Castriciano, junto aos homens intelectuais da cidade de Natal, como por exemplo o "Dr. Manoel Dantas, Dr. Francisco Meira e Sá, Dr. Juvenal Lamartine, Dr. José Augusto, Dr. Dionysio Filgueira, homens de letras, [...], interessados no desenvolvimento do Estado" (Barros, 2000, p. 40-41).

O apoio deles foi essencial para que a Liga de Ensino do Rio Grande do Norte - LERN, fosse fundada em 1911 e posteriormente a Escola Doméstica de Natal, em 1914. Um dos objetivos da Liga era o de "auxiliar os poderes públicos em tudo quanto disser respeito à instrução e educação do povo, e em particular, fundar escolas para a instrução e educação da mulher" (Cascudo, 2008, p. 163). Ademais, a Liga de ensino idealizou um modelo de educação, e a Escola Doméstica foi fundada para "fazer a diferença", a medida que "defendia uma educação onde a mulher fosse instruída para que, no lar ou fora dele, soubesse guiar-se nos caminhos da vida", aponta Barros (2000, p. 91).

Professoras estrangeiras, diplomadas pela École Ménagère de Friburgo, foram trazidas para compor o corpo docente da escola, houveram alguns percalços para que elas fossem contratadas, mas Henrique Castriciano sabia que era importante tê-las nesse início. Por isso confiou ao governador Alberto Maranhão o pedido que fizera, de levar "ao Ministro do Brasil na Suíça, Raul do Rio Branco, para a contratação de duas professoras diplomadas", [...], sendo "atendido com a intervenção do Ministro do Exterior Lauro Muller".

Inicialmente foi apresentado o nome de "duas jovens professoras" - Hélène Bondoc e Jeanne Negulesco, Barros, (2000, p. 75) apresenta os benefícios que a administração delas trouxeram para o bom funcionamento da instituição. O currículo trazia características delas. Mlle Hélène Bondoc - foi primeira Diretora da Escola, exercendo sua função durante um ano (1914-1915), a Mlle. Jeane Negulesco, assumiu a diretoria nos anos de 1915 a 1918. Até 1926 a escola teve outras professoras estrangeiras que exerceram o cargo de direção e somente a partir de 1927 uma brasileira assume o posto de diretora da instituição, a Sta. Maria Emiliana Silva (1927-1930).

\footnotetext{
3 Lima, D. P. C. Noilde Ramalho: uma história de amor à educação. Natal: Liga de Ensino do Rio Grande do Norte, 2004. p. 237

4 Idem., 2004, p. 240 e 241.
} 


\subsection{Educação escolar, a identidade de uma escola feminina}

Um dos pontos principais que representava a educação feminina à época era a organização do lar, haviam também ensinamentos que as preparavam para exercer um ofício. A Escola Doméstica refletia o modelo suíço, conforme dito anteriormente, e esse molde formulou “um conteúdo curricular voltado para a criação do 'espírito moderno', no qual a escola passa a ser o espaço privilegiado para a propagação de um novo modelo social e para a criação de uma nova moral para a sociedade" (Pinheiro, 2005, p. 25). A idealização de Castriciano pode ser resumida em

Uma Escola Doméstica, à semelhança das que a previdência dos povos cultos desde muito vem fundando em larga escala, nos grandes e pequenos núcleos; em que, ao lado do indispensável ensino teórico, sejam ministrados seguros conhecimentos práticos, que habilitem a mulher a velar criteriosamente pela educação física, intelectual e moral dos filhos, orientando o espírito dela de modo a poder viver por si, no caso de faltar o apoio dos que lhe servem de arrimo; uma escola assim representa por certo o início de uma promissora fase social, porque é da mulher que depende a felicidade da família e esta é a nação em miniatura (Cascudo, 2008, p. 164 e 165).

Ao afirmar que "os Estados almejam mulheres instruídas para a educação básica das crianças. O mercado de trabalho precisava de mulheres qualificadas, principalmente no setor terciário de serviços: correios, datilógrafas, secretárias [...]” Perrot (2007, p. 92) reitera que o modelo de sociedade era idealizado através da educação feminina, era na verdade para deixá-las instruídas para o processo de criação dos filhos que viesse ter.

A educação das classes abastardas mostrava que era necessário os privilégios de quem tinha acesso ao melhor ensino educacional, a elite se fortificava, pois estava priorizando mudanças na educação feminina, ao pensar na padronização coletiva, eles escreveram o ideal de um povo, e que somente seria alcançado instruindo as mulheres com o melhor que a escolar pudesse oferecer e claro, elas pudessem pagar.

A liga de Ensino não tinha por finalidade “a emancipação da mulher nem encaminhá-la para a solução do que se convencionou apelidar de feminismo". Cascudo (2008, p. 164) assegura que o "principal objetivo da Liga pode ser resumido em quatro palavras: aperfeiçoar a educação doméstica”. Não obstante, a qualquer empecilho, a educação feminina conduzia as moças para sua emancipação, ao proporcionar-lhes uma educação com qualidade, induzindo-as a refletir acerca do contexto social em que se encontravam. Tendo em vista essa afirmação, a escola doméstica foi administrada por mulheres letradas e independentes, capacitadas para promover uma educação com qualidade.

Rodrigues (2007, p. 54) afirma que

A Liga surgiu da necessidade de intelectuais e políticos norte-rio-grandenses, [...], criarem uma entidade que congregasse os seus ideais e reunisse esforços em função da concretização dos seus propósitos sociais e republicanos. [...] Manifestaram a necessidade de renovar o ensino potiguar que consideravam arcaico, ultrapassado em seus métodos de ensino, quando no Brasil eram fundadas, em várias cidades, Ligas e/ou entidades congregadoras de ideias, na sua maioria, de cunho nacionalista, cívica e embrionariamente partidária.

Uma carta de Henrique Castriciano com a data de maio de 1911, detalhava a importância que a criação de uma escola feminina tinha para a educação, pois era a representação de uma "promissora fase inicial, porque é da mulher que depende a felicidade da família e essa, é a nação em miniatura" (Barros, 2000, p. 42). Nisto ele afirmou que a mulher era responsável na formação dos filhos e das filhas, pois era comum que a maioria das mulheres ficassem em casa com os cuidados domésticos. Era urgente que houvesse "a criação de uma escola em orientação técnica na ciência da dona de casa", fundamental para educar e instruir a mulher do campo e da cidade. Segundo o entendimento de Miranda (2021, p. 32, no prelo)

Planejar uma educação feminina que trouxesse ensinamentos comportamentais e ainda noções técnicas de como gerenciar seu lar e educar de forma culta os filhos ou demais crianças, era o modo mais adequado aos olhos dos homens 
intelectuais da Liga de Ensino para formar cidadãos cultos que fossem úteis para sua nação. Instruindo-lhes em seus comportamentos e atitudes, influenciando até mesmo nas suas vestimentas, visando atender as demandas de uma sociedade que ansiava estabelecer um modelo de comportamento para o seu povo.

A autora reitera que o desejo de modernizar e ter uma sociedade educada à custa da escola, tornou a mulher responsável em partilhar nos lares esses saberes, bem como ter do governo as ações necessárias para que houvesse um planejamento voltado para os problemas de analfabetismo existentes na sociedade, seria a "nova e augusta maternidade: a formação social do Brasil de amanhã” (BARROS, 2000, p. 43). Portanto, ao concluir seu curso, as alunas da Escola Doméstica estavam aptas para lecionar, e o nível curricular, estabelecido para a formação delas, as tornava qualificadas para atuarem no campo da educação. (Miranda, 2021, p. 33, no prelo).

Para atender as demandas da sociedade era necessário entender que "a modernidade torna-se então o atingir dos limites, a aventura da marginalidade, e já não a conformidade à norma, o refúgio na autoridade, a ligação ao centro, que o culto do “antigo" sugere”. (Le Goff, 1990, p. 167). Em poucas palavras, Miranda (2021, p. 33, no prelo) aduz que todo o entendimento de modernidade para a época ultrapassou a compreensão do que era o processo de instituição de uma escola feminina aos moldes europeus. Tornando a escola uma referência em educação para a sociedade, devido ao modo arrojado e eficaz do seu processo de ensino e aprendizagem à época.

Ao dialogar com Saviani (2005, p. 28), podemos relacionar o conceito de instituição ao significado de escola, a partir dos quatro significados que ela pode ser descrita: planejar, ensinar, capacitar e desenvolver o conhecimento. A instituição escolar precisava atender os ideais de uma educação suíça e ao mesmo tempo colocá-la sob a ótica do regionalismo potiguar entendido pela elite. O objetivo era que as alunas desenvolvessem os conhecimentos necessários que a sociedade propunha, sob a percepção de Cunha (1986) citado por Rodrigues (2007, p. 101), a escola deveria ser "representativa e democrática, que se caracterizasse como mantenedora dos valores humanos, mas também formadora de cidadãos conscientes de suas responsabilidades e direitos perante o social; uma escola agilizadora do processo de desenvolvimento social do país”.

O público inicial eram as moças residentes em Natal, e posteriormente a escola passou a receber alunas vindas do interior do RN e vindas de outros Estados do Brasil. Em outros termos, Miranda (2021, p. 33, no prelo) afirma que o "modelo para a educação feminina, está atrelado a organização, e com uma estrutura curricular voltada aos ideais desejados para o ensino da mulher, [com vistas a torná-la] diferente das demais instituições escolares”. Sobre o fato Saviani (2005, p. 28), reitera que

As instituições escolares são, portanto, necessariamente sociais, tanto na origem, já que determinadas pelas necessidades postas pelas relações entre os homens, como no seu próprio funcionamento, uma vez que se constituem como um conjunto de agentes que travam relações entre si e com a sociedade a que servem.

Segundo Rodrigues (2007, p. 102), a escola apresentou "significados nos discursos de intelectuais e políticos da época”, trazendo contribuições indispensáveis para que houvesse concretização dos valores coletivos - morais, intelectuais, culturais investindo na prática desse aprendizado, posto que foi uma prática de aprendizagem que a escola adotou tendo como foco o contexto social, e por conseguinte, sendo benéfico para a sociedade, embora se adaptasse ao modelo "produtivo que despontava com o crescimento industrial, nas fábricas e no mercado, exigindo da escola uma cultura de formação que passasse a privilegiar a pedagogia e seus elos com os objetivos políticos e culturais da sociedade vigente” (Rodrigues, 2007, p. 102).

Nesse sentido, "implicando a existência de uma multiplicidade de culturas" em seu interior, principalmente por ser um ambiente que tem um público diverso, que trazem consigo suas experiências e práticas adquiridos em sua vida cotidiana (Saviani, 2005 , p. 30).

Entretanto, o caminho percorrido pelas mulheres era longo, principalmente ao requerer seu espaço na educação, os cursos direcionado para as mulheres eram diferentes dos que eram ofertados aos homens, nesse pensamento, a mulher da elite 
passou a reivindicar sua participação na construção do currículo escolar feminino que era elaborado somente pelos homens, muitas vezes eles induziam qual tipo de instrução elas deveriam ter. Perrot (2007, p. 95) afirma que elas, "reivindicaram muito cedo o direito à instrução. [...] não confiavam no ensino que concediam a elas. Temiam sua desvalorização".

A “a cultura escolar é descrita como um conjunto de normas que definem conhecimentos a ensinar e condutas a inculcar, e um conjunto de práticas que permitem a transmissão desses conhecimentos e a incorporação desses comportamentos," Júlia (2001, p. 9) nos faz perceber que na organização das normas da Escola havia uma preocupação em manter um padrão na formação das alunas. Todo programa de ensino foi minuciosamente elaborado para atender às solicitações da Liga de Ensino do Rio Grande do Norte. Apesar de ter em sua essência a instrução das diretoras estrangeiras, foi percebido que a Liga de Ensino direcionava aos moldes dele a condução do conteúdo aplicado.

Fundada para "fazer a diferença", embora que "defendia uma educação onde a mulher fosse instruída para que, no lar ou fora dele, soubesse guiar-se nos caminhos da vida", expõe Barros (2000, p. 91). As transformações fazem parte da trajetória da escola, sendo assim, as alunas desenvolviam habilidades, sendo instruídas para se apresentarem a uma vida social recatada e culta, independente de ser da cidade ou do campo.

Formadas não somente para conduzir o lar, as alunas recebiam uma educação que desse capacitação necessária para que possam ser habilitadas a serem inseridas no mercado de trabalho. A elaboração curricular possibilitou a contemplação das "matérias práticas e teóricas, o qual seria trabalhado pela educação e pela instrução, levando a aluna, ao final do curso, à aptidão para as elites domésticas e para os desafios da vida, pelos conhecimentos e cultura adquirido. (Lima, 2004, p. 241).

O pioneirismo da Escola Doméstica promoveu uma educação que rompeu os ideais enraizados de outras instituições escolares femininas ao promover que rompeu paradigmas de quais eram as funções do homem e da mulher diante daquela sociedade. Perrot (2007, p. 91), assevera que "o saber é contrário à feminilidade", e que o direito ao saber e aprender era privilégio exclusivo do homem, sendo assim, havia punição para a mulher que estivesse estudando.

Um currículo bem elaborado, pensando na sociedade que a escola está inserida e o público alvo, torna-se mais alinhado aos conceitos da prática e da cultura escolar. Esses conceitos foram muito relevantes ao influir a organização curricular da instituição brasileira, "sendo estabelecida a ideia de organização e desenvolvimento" (Silva, 2013, p. 24-25). O currículo da Escola Doméstica seguia uma organização impecável, posto que as alunas a cada etapa de ensino sequenciava um cronograma de aprendizados, que seriam pré-requisitos para as disciplinas dos anos seguintes.

A cultura escolar recebeu influência externa, e isso foi possível por causa das relações que a escola tinha com a sociedade, além disto, as características do público alvo e os funcionários que compunham a equipe pedagógica, eram tinham particularidades que não eram encontradas em outras instituições.

\subsection{A Puericultura}

Puericultura é o "resultado de pesquisas na área da saúde em diferentes campos como Nutrição, Antropometria, Imunologia, Psicologia e Odontologia", afirma Bonilha \& Rivorêdo (2005, p. 7). No âmbito educacional os ensinamentos técnicos voltados para o cuidado da infância foram importante pois possibilitou um olhar mais meticuloso sobre o saber fazer na infância.

O termo Puericultura significa PUER: criança e CULTURA: cuidado, criação. Foi usado a primeira vez por Jacques Ballexserd, médico e pesquisador atuante nos anos de 1726-1774, em 21 de maio de 1762, em Genebra, Suíça, ao escrever "A dissertação sobre a educação física das crianças" ". Nesse livro ele traz conceitos e instruções que corroboram com o cuidado da infância.

5 Título original: Dissertation sur L'éducation Physique Des Enfants. Giordanengo (2019, sn). Disponível em: https://bibulyon.hypotheses.org/12625. 
Para Ballexser era preocupante a enorme demanda da mortalidade infantil, entre crianças com até dois anos de idade e no século XVIII causou alvoroço, passando a ser objeto de estudo, buscando compreender o comportamento da sociedade diante daquele mal, buscando identificar e propor soluções que reduzisse os índices de mortalidade que potencialmente atingia as crianças, independente de sua condição social. Segundo Miranda (2021, p. 53, no prelo), “os primeiros indícios dos pensamentos progressistas foram vistos em seus escritos, para ele se as classes mais abastadas recebessem essas noções de higiene e cuidados, as classe menos favorecidas iriam seguir o exemplo".

Jacques Ballexserd ${ }^{6}$, aconselhava que fossem promovidas ações que instruísse a sociedade no cuidado da infância, com vistas a entender o fortalecimento da saúde da criança. Nessas ações ele indicavam como deveriam ser feitas as lavagens das roupas, a higienização e o preparo dos alimentos, além de incentivar a prática de atividades físicas, por exemplo. Suas contribuições corroboraram para que as doenças fossem identificadas e tratadas a tempo, e assim evitando uma morte precoce das crianças. Ele era um incentivador do aleitamento materno, pois em suas pesquisas entendeu que o leite materno protegia a saúde das crianças e lhes proporcionavam um crescimento saudável. Apesar da sua importância para o desenvolvimento infantil, a pesquisa de Ballexserd não teve incentivadores.

As sociedades passaram a se preocupar com a mortalidade infantil, pois o seu aumento implicaria na redução de força adulta, sendo inclusive proposta de ensino, e foi por meio da educação, que muitas famílias entenderam a importância desse cuidado para os pequenos infantes. Bonilha e Rivoredo (2005, p. 8), trazem afirmações que por esses ideais tinham propósitos de padronizar a sociedade, estabelecendo um modelo comportamental, não somente "para as crianças, mas para as famílias como um todo, de cunho moralizante e baseado naquele considerado ideal pelas classes dominantes [...].”

A puericultura representaria a consolidação de um projeto iniciado na Europa, no século 18, que visava à conservação das crianças, essencial para os grandes Estados modernos, os quais mediam as suas forças pelo tamanho de seus mercados e exércitos" (Bonilha \& Rivorêdo, 2005, p. 8).

O manual publicado em 1865, de autoria do médico francês - Alfred Caron, A Puericultura ou a ciência de elevar higienicamente e fisiologicamente as crianças, descreve que era possível ter sido evitada as muitas doenças ou internações na infancia se suas mães fossem instruídas corretamente para a amamentar, preparar os alimentos, organizar as vestimentas além de aprenderem a ter os cuidados higiênicos de seus filhos de forma adequada. Portanto, foi entendido que a educação feminina deveria contemplar esses ensinamentos, e que tais habilidades deveriam ser também direcionadas às moças carentes.

Era fundamental que a criança recebesse o acompanhamento desde a sua concepção, ainda sendo gerada por sua mãe, esse cuidado promovia uma atenção essencial para verificar indícios de possíveis doenças que a criança viesse ter e também para prevenir uma morte intrauterina, que também era comum quando a gestante não recebia o acompanhamento no que hoje chamamos pré-natal, ou período que antecede o natalício desse pequeno infante.

A proposta era orientar as mães para receber um acompanhamento nutricional e praticar atividades físicas, evitando que fossem acometidas por uma diabetes gestacional ou pressão alta e ainda comprometer sua alimentação causando sua desnutrição da criança que estava sendo ou viesse a ser gerada. Esses ensinamentos foram aprofundados e é por isso que hoje as mulheres passam a ser acompanhadas por médicos especializados, dando o máximo de atenção à gestação.

\footnotetext{
${ }^{6}$ Jacques Ballexserd (1726 - 1774), nasceu em Genebra. “Deixou um nome na história da pedagogia por ser um dos primeiros a se interessar pela educação do ponto de vista médico. Ele foi influenciado por John Locke e Jean-Jacques Rousseau, que, em suas Confissões (II,9), o acusa de plágio. Suas duas obras, sobre a educação física infantil (Paris 1762, Yverdon 1763) e sobre mortalidade infantil (1775), foram coroadas pelas academias do Harlem e de Mântua e foram tema de várias edições". (Barras, 2001, np). (Disponível em: https://hls-dhs-dss.ch/fr/articles/019723/2001-12-27/).
} 
Ao corroborar com Saparolli (2012, p. 2), entendemos que "estudos mostram que deficits de crescimento linear que ocorram até os dois anos (principalmente no primeiro ano de vida) são passíveis de recuperação total, enquanto acima dessa idade a reversibilidade desse quadro se torna bem mais difícil”. Nos fazendo constatar que

O desenvolvimento caracteriza-se como um processo global e dinâmico de mudanças que ocorrem em uma pessoa, desde sua concepção, influenciado por diversos fatores físicos, entre eles os cuidados com a alimentação, a higiene e a prevenção de doenças, além da dimensão psicológica, ligada a fatores psíquicos que estão relacionados à forma como uma criança aprende e relaciona com o ambiente em que vive. Dessa maneira o desenvolvimento é compreendido como um processo mais amplo, envolvendo o crescimento e aprendizagem da criança (Saparolli, 2012, p. 04)

O Dr. Carlos Arthur Moncorvo Filho, foi o precursor sobre os estudos da Puericultura no Brasil, em 1899 ele iniciava suas ações no que diz respeito à proteção da criança. Fundou o primeiro Instituto de Proteção e Assistência à Infância do Rio de Janeiro, algumas atribuições foram descritas por ele, conforme é apresentado abaixo por Nunes. (Corsino \& Didonet, 2011, p. 19).

Ao Instituto foram atribuídos objetivos bastante amplos e diversificados: (a) atender aos menores de 8 anos, (b) elaborar leis que regulassem a vida e a saúde dos recém-nascidos, (c) regular o serviço das amas de leite, (d) velar pelos menores trabalhadores e criminosos, (e) atender as crianças pobres, doentes, defeituosas, maltratadas e moralmente abandonadas, (f) criar maternidades, creches e jardins de infância. [...] Ofereceu um modelo organizacional e institucional ao governo sobre a assistência à criança pobre.

A criança desvalida precisava ser protegida, pois a sua vida era regada de vários infortúnios, dentre eles o acesso mínimo às condições básicas de higiene, por isso que o médico se preocupava em passar os ensinamentos às suas mães ou cuidadoras, essa privação tratava-se "portanto, de um argumento adicional para segmentar e propor determinadas experiências para as crianças marcadas por seus caracteres físicos, mas também por condições sociais distintas”. Rizzini e Gondra (2014, p. 568). Muitas dessas perdas aconteciam por falta de ensinamentos, cuidados com a higiene e alimentação, portanto ambos foram direcionados às mães que frequentemente não saberiam como proceder.

Em conformidade com Miranda (2021, p. 55, no prelo)

Anteriormente a temática das crianças em condições de risco foi fortemente debatida pelos médicos da Faculdade de Medicina do Rio de Janeiro no século XIX, os discursos higienistas direcionaram as atenções especialmente para os pobres. Uma rede de proteção à infância desvalida foi formada, pois havia muitas sendo deixadas na roda dos expostos, tornando a situação delas principalmente as que não tinham amparo, a cada momento mais preocupante, principalmente pela alta mortalidade nos primeiros anos de vida dos pequenos, muitas crianças eram abandonadas com um estado de saúde delicado, aumentando seu risco de morte.

Gondra (2000, p. 104) alega que a situação tinha proporções de austeridade com o número de crianças debilitadas ou mortas deixadas na roda dos expostos, o percentual era alto, sendo recomendado que as crianças fossem alinhadas "segundo os preceitos da higiene, sob a pena de ser mantido o alarmante índice de mortalidade", o autor ainda descreve que chegou a $82 \%$ o índice de mortes. Eventualmente, as crianças eram expostas aos mais diversos tipos de maus tratos, esses lhes causavam também desnutrição e por conseguinte o abandono, sendo deixados nas ruas ou em locais sem o mínimo de higiene. Muitas dessas crianças foram abandonadas nas rodas dos expostos ainda muito pequenas, essa fuga se dava também devido o espaço que era insuficiente para o volume de crianças abandonadas que chegavam diariamente.

Além disso, Gondra (2000, p. 104), relata que as 
[...] poucas acomodações para o número de crianças recebidas, falta de vigilância necessária, surtos epidêmicos de oftalmias, desinterias, tubérculos mesentéricos, sarampões e bexigas, contato entre os doentes, aleitamento coletivo, desprezo às regras de asseio e falta de equipamentos necessários à realização de algumas atividades clínicas

Motivavam que quando estivessem maiores, as crianças iriam fugir daquele ambiente, com ressalvas, as que conseguiriam sobreviver a todas essas moléstias as quais estava expostas.

A construção de abrigos para essas crianças não era a solução para a redução da mortalidade, era necessário instruir as jovens moças a terem cuidados com sua saúde sexual, instruindo-as para quando fossem gerar filhos, e fazer o acompanhamento quando estivessem grávidas. O intuito era prevenir o falecimento precoce da criança e em alguns casos da própria mãe, que por faltas de recursos e acompanhamentos adequados perdia sua vida durante a gestação, no parto ou no pós parto.

Por essa razão, a importância da instituição de um espaço voltado para esses cuidado foi essencial para que fossem iniciados os acompanhamentos no período gestacional, no parto ou pós-parto, o IPAI RJ - Instituto de Proteção e Assistência à Infância do Rio de Janeiro é um exemplo de espaço de acolhimento especifico para as crianças e suas mães.

Corroboramos com Bonilha (2004, p. 61) quando descreve que o ensino era idêntico ao da Europa, naturalmente atribuía a falta de conhecimento da mãe, qualquer mazela que a criança adquirisse. Acompanhá-las, estava dentro da proposta do projeto, "educando-as até modificarem seus costumes, ou seja, moralizá-las". Além de padronizar a sociedade, havia um interesse em mascarar a condição de vida das familias pobres, bem como controlar a natalidade. De certa forma também auxiliava para terem cuidados em seu período gestacional.

Era entendida a importância da prevenção à mortalidade infantil, a condução dessa medida era voltada para a classe alta da sociedade. No entanto, as intervenções médicas eram conduzidas para os menos favorecidos financeiramente. O interesse da elite era o a proteção das suas crianças das possíveis moléstias adquiridas no convívio com as crianças desvalidas, afirmando o preconceito existente. Confirmamos com Bonilha (2004, p. 63), sobre suas considerações a respeito da puericultura no Brasil ter "um forte teor moralista e de discriminação entre ricos e pobre [...]".

O estudo da Puericultura reforça que é prudente iniciar o cuidado com a criança na sua mais tenra idade, pois ela estará mais preparada em sua idade adulta. As alunas da Escola Doméstica recebiam ensinamentos que podiam ser praticados, o currículo da escola contemplava essa aplicação da teoria com a prática, Rodrigues (2007, p. 168) afirma que,

Durante uma aula de Puericultura, refletia um dos momentos de expectativa das discentes, que era pôr em prática os conhecimentos estudados durante as aulas Puericultura, pois a discente deveria vivenciar durante uma semana as práticas referentes aos cuidados de saúde, higiene e nutrição de uma criança.

Segundo Miranda (2021, p. 58, no prelo),

Em sua maioria o público alvo eram as crianças pobres, descendentes de escravos, indígenas, abandonadas, órfãs e com deficiência, apesar de nos textos lidos não encontrarmos de forma direta a ligação entre a Puericultura e a educação, nós compreendemos que pelos dados históricos e os acontecimentos ocorridos nos momentos que ocasionaram o início desse cuidado com a infância, o Brasil caminhava na construção de conceitos que trouxessem integração tanto no cuidado como no educar a criança.

A História da primeira infância do Brasil no decorrer dos séculos XIX e XX foi passando por mudanças e implementações voltadas para o cuidado com a criança. Nunes, Corsino \& Didonet (2011, p. 13), reitera que "no âmbito teórico ou conceitual das ciências que estudam a criança [...] sobre a primeira infância, que a criança é um todo, que o físico, o social, o emocional e o intelectual são apenas aspectos de um ser único e integral e que um não se realiza bem sem os outros." 
Além disso, "a construção da infância historicamente depende muito da construção de outros sujeitos. [...] A mulher e a infância sempre estiveram próximos. [...] Dependendo do papel da mulher na sociedade, [é possível] encontrar um papel diferente para a infância", aduz Arroyo (1994, p. 89). Segundo Miranda (2021, p. 59), "a mulher em determinados momentos é vista como senhora de sua casa, a que dá equilíbrio ao lar, principalmente quando compreende que esse desígnio é pertinente à sua construção social, nos valores inculcados no ambiente social, cultural e histórico".

Nunes, Corsino \& Didonet (2011, p. 17), afirmam que as iniciativas de atendimento à criança deram início no final do séc. XIX até os anos de 1985, aproximadamente. Sendo influenciados pela educação proposta da Europa, e foram nesses ensinos que passamos a entender a sistemática dos jardins de infância e das creches. As crianças filhas das mães trabalhadoras eram matriculadas nas creches, assim como as crianças que estivessem a margem da sociedade, tinha uma estrutura que auxiliava as mães enquanto estavam exercendo o seu ofício. Diferente das crianças que iam para os jardins de infância, pois a sua presença nesse ambiente escolar era exclusivamente para aprender as primeiras letras, atendendo apenas as crianças das classes abastadas.

Ratificamos quando Nunes, Corsino \& Didonet (2011, p. 17 e 18), relatam que "as condições econômicas eram fatores que influíam fortemente no tipo de instituição que as crianças eram atendidas". Elas tinham objetivos e atividades que interagia diretamente ao tipo de suporte recomendado. "O cuidado físico, saúde, alimentação, formação de hábitos de higiene, comportamentos sociais", eram propostas das creches, incluíam também as "orientações à família sobre cuidados sanitários, higiênicos pessoais e ambientais, orientações sobre amamentação e desmame, preparação de alimentos e relacionamento afetivo"

O ensino da puericultura, preparava as alunas no cuidado das crianças pensando no futuro, por vezes não levando em consideração o presente, e nem muito menos a realidade de vida delas. Desde pequeninas, as crianças eram direcionadas para a sua vida na fase adulta. As escolhas durante a infância definiriam o futuro daquela criança em observação. A prioridade era a redução da mortalidade infantil.

O olhar para educação feminina prioriza o cuidado pessoal e com a criança. Nos ensinamentos propostos no ambiente da Escola Doméstica, a mulher recebia as instruções adequadas para que pudessem ser partícipes na formação de um novo sujeito social, aquele idealizado pela sociedade elitizada, no qual as crianças eram bem-educadas e os adultos cidadãos promissores para a nação. Aduz (Miranda, p. 59, no prelo).

A história da Puericultura no Rio Grande do Norte, está ligada ao médico e professor o Dr. Varela Santiago Sobrinho . Ao analisarmos a trajetória profissional do médico percebemos que ao longo do seu percurso ele teve uma vida dedicada à filantropia. A começar em 1913, quando passou a atender gratuitamente os doentes das regiões mais carentes da cidade, reservando três dias da semana, uma hora cada. Em 1915, passou a lecionar na Escola Doméstica.

Em 1916, ele dedicou o atendimento às crianças do Grupo Escolar Frei Miguelinho, Galvão (2017, p. 79) afirma que era "uma cooperativa destinada a amparar os alunos do estabelecimento que, em sua maioria, eram oriundos de famílias carentes do bairro do Alecrim"9. As visitas aconteciam regularmente, as crianças eram examinadas e medicadas quando necessário, essa empreitada contava com o apoio do farmacêutico Joaquim Torres, pois ele fornecia gratuitamente os medicamentos.

\footnotetext{
7 Nunes; Corsino; Didonet (2011, p. 17 e 18).

${ }^{8}$ Manoel Varela Santiago Sobrinho, nasceu no Engenho Boa Vista, na cidade de Touros, município do Rio Grande do Norte, no dia 28 de abril de 1885 . Filho de Cândido Xavier Varela e Rita da Costa e Silva. Formou-se pela Faculdade Nacional do Rio de Janeiro em 1910; também na Faculdade de Medicina da Bahia e fez o curso de Humanidades no Atheneu Norte-rio-grandense. Casou-se com Maria de Lourdes Lamartine. Fundador do IPAI; também exerceu a função de diretor do departamento de saúde do Estado do RN nos anos de 1924-1930; fundou a Colônia São Francisco de Assis; fundou o Educandário Oswaldo Cruz; foi presidente da Liga de Ensino do Rio Grande do Norte; professor de Puericultura na Escola Doméstica. (FERNANDES, 2016, p. 8-9).

9 GALVÃO, 2017, p. 79. O historiador relata detalhadamente a História do Dr. varela Santiago. A obra encontra-se disponível no Hospital Infantil Varela Santiago, e todo o seu valor é revertido para custeio do hospital.
} 
Em 12 de outubro de 1917, ele fundou o Instituto de Proteção e Assistência à Infância do Rio Grande do Norte - IPAI, com sede em Natal. Atendendo um pedido do Dr. Arthur Moncorvo Filho, que foi o idealizador do IPAI / RJ. Foi através do IPAI que o cuidado com a infância foi intensificado. O atendimento era organizado na sala de sua casa "e recebia crianças carentes, para quem dava atendimento gratuito, fornecendo cuidados necessários como prevenção a mortalidade infantil que era comum”, conforme afirma Fernandes (2016, p. 12).

Em 11 de agosto de 1919, foi inaugurado o Instituto de Puericultura da Escola Doméstica de Natal, sendo o marco referencial do ensino da Puericultura em contexto escolar para a educação feminina, até este tempo, o ensino era desenvolvido apenas nas Escolas de Medicina no país. O pavilhão de Puericultura tinha sala para exames e para as aulas, bem como recursos necessários para a aplicação das aulas, conforme Fernandes (2016, p. 32) apresenta,

Balanças, antropômetro, mesa, cozinha dietética, berçário com divisórias, banheira própria para recém-nascido, aquecedor de água, paredes revestidas de azulejos [para controle da higienização], [além de] apartamentos para uso das alunas escaladas como 'mãe' e 'ajudante'.

O currículo do ensino da Puericultura priorizava ações que instruí-se a mulher com os cuidados na higiene do lar e a saúde da criança na sua primeira infância. Ao final do curso, as alunas eram capazes de entender a importância da higiene para manter o lar saudável, tinham capacidade de identificar quando as crianças estavam doentes, buscando o tratamento adequado, pois anteriormente para cursar Puericultura, elas deveriam ter pago as cadeiras de medicina e enfermagem, pois era pré requisito para que a aluna tivesse noções científicas na área médica.

As crianças selecionadas, ficavam sob os cuidados da escola durante seis meses, nesse período as alunas faziam atividades investigativas, tomando nota de toda a evolução da criança observada, Miranda (2021, p. 65, no prelo) aduz que

No internamento todos os dados das crianças eram registrados em uma ficha. Nela também eram anotadas todas as ações diárias realizadas pelas alunas - que eram as mães do plantão. Tudo deveria ser anotado, desde as condições de saúde, passando pela verificação das suas funções vitais, como temperatura, pulsação, até as condições como: higiene, alimentação, banhos de sol, peso etc.

Galvão (2017, p. 104) reitera que,

A instituição, que foi a primeira escola feminina no Brasil era, na ocasião, a única que praticava a Puericultura em instalações apropriadas e que acolhia crianças como internas, recebendo os cuidados das alunas e do professor da disciplina. Um cuidado especial foi adotado: as crianças, que eram na sua maioria originárias de famílias de baixa renda, ao retornarem para as suas casas passavam os seus pais a receberem do Instituto de Proteção e Assistência à Infância uma ajuda em forma do fornecimento de leite.

Era notória a preocupação do Dr. Varela Santiago com o alto índice de mortalidade infantil. Por isso em outubro de 1925 , ele publicou na Revista Escola Doméstica que essa mortalidade era decorrente da falta com os cuidados higiênicos da população, a cultura sanitária não era extendida aos mais pobres, muitas vezes viviam em regiões que não tinha o básico como água potável ou um aterro sanitário, razão que causava tantas mortes principalmente entre as crianças. Esse era um interesse mundial, pois foi uma época que houveram muitas mortes de crianças, independente das condições e circunstâncias que elas estavam.

Ao longo da nossa leitura, compreendemos que a a mulher é colocada como principal responsável pelas doenças que as crianças adquiriam, que muitas vezes por falta de cuidados adequados elas vinham a óbito. A falta de ensinamento para a mulher atingia diretamente as crianças, por isso foi pensada uma educação que trouxesse esses ensinamentos específicos para as mulheres. Por esta razão, que Varela Santiago foi bastante criterioso com os equipamentos, estruturação do espaço, elaboração 
do currículo proposto para o ensino da Puericultura, pois queria proporcionar um ensinamento de qualidade com os melhores recursos disponíveis à época.

Corroboramos com Miranda (2021, p. 63, no prelo) quando relata que

$\mathrm{O}$ seu cronograma de ensino tinha a preocupação em priorizar os ensinamentos voltados à mulher naquilo que se referia a higiene do lar e a saúde da criança, principalmente, preparando-as para que saibam se comportar em casa ou em qualquer ambiente social, além de instruí-las sobre a organização adequada de um lar.

O crescimento saudável das crianças e os cuidados com a própria saúde eram necessários para que a mulher se tornasse capaz de lidar no momento que estivesse grávida.

Elisabeth Badinter, salienta que a maternidade é "aureolada" de amor, "amor a mais", essa expressão descreve o crescimento do sentimento maternal, já a partir do século XVII, e o da figura da mãe, tanto nas práticas (saúde, puericultura, educação na infância) quanto na simbólica" Um dos traços mais marcantes da época contemporânea reside na politização da maternidade, tanto nos Estados totalitários quanto na República. (Perrot, 2007, p. 69).

O estudo da Puericultura na educação, abriu portas para que novos olhares fossem direcionados para o cuidado com a infância, no RN, o projeto foi pioneiro, e mesmo após a instituição desse ensino na Escola Doméstica, outros centros voltados para o ensino da Puericultura foram ofertados, o público alvo eram as moças solteiras e as mães de família, de Natal e Caicó. A Legião Brasileira de Assistência dava todo o apoio para a condução do curso. (Galvão, 2017, p. 327).

\section{Conclusão}

O modelo de educação ideal para a mulher foi recebida com bons olhos. Esse foi o momento oportuno para que a sua condição diante da sociedade fosse a outro nível. Além de direcioná-las ao estilo de vida que elas seguiriam. O currículo da educação feminina avançou muito, a proposta era torná-la independente, e que compreendia o seu valor. Aproveitar a oportunidade e prosseguir com os estudos, lhes garantiria uma vida profissional com mais oportunidades. Além de serem integradas socialmente podendo exercer seus direitos e deveres enquanto cidadãs.

A mulher que antes vivia em seus casarões a mercê dos empregados, se reinventou, e foi capaz de colocar seus sonhos e planos como prioridade, as circunstâncias que elas viviam por vezes eram de repressão. A mulher remodelada do século XX, foi conectada à modernidade, moda, apreciadora das belas artes e música, era interessada em conhecer novos ambientes, tudo isso por que lhe foi permitido ser participante do projeto de educação escolar.

Era notório que a sociedade natalense ansiava por modernidade, e ela precisava sair do papel. A infraestrutura, a educação, as artes, foram incutidas na vida cotidiana dos potiguares. Mesmo como receios, e a passos lentos, essa inserção proporcionou mudanças na rotina dos cidadãos.

Miranda (2021, p. 67, no prelo) afirma que com advento da

República, o pensamento de modernidade tomava conta dos brasileiros, o espírito revolucionário e o desejo de seguir o exemplo dos países evoluídos foi motivo para muitos embates. Em Natal houve resistência, no entanto, foi entendido que algumas mudanças eram necessárias. Formar cidadãos comprometidos com o seu povo, era imprescindível para o desenvolvimento da sociedade. Foi a partir desse pensamento que o discurso de padronização coletiva foi sendo inculcado na mente dos mais letrados e também das pessoas que vivenciavam esses desejos. Este estudo apresentou a organização da sociedade com os olhos voltados para uma instituição de ensino direcionada para a educação feminina, quando, à época, a palavra de ordem era modernizar o ensino para as mulheres aos moldes da educação ofertada na Europa. Pretendia-se, portanto, um modelo de escola laica, que se preocupasse, entre outras coisas, em ensinar a mulher sobre a ciência da dona de casa, com estudos teóricos e práticos. Fundar uma escola que promovesse uma educação completa e culta para as mulheres potiguares e de estados vizinhos, foi o primeiro passo para que a elite norte-rio-grandense visse refletido nos seus desejos, a ideia de modernidade no ensino. A Escola Doméstica foi pensada por homens que desejavam definir o tipo de educação que a mulher deveria receber e qual finalidade desse aprendizado. 
Foi pensando em tudo, desde a escolha da sede até a contratação da diretoria - que acabou sendo formada por estrangeiras, visto que, a formação delas era a mais adequada para atender aos ideais propostos inicialmente. A estrutura física da escola, as vestimentas a serem usadas, o público a que se destinaria, entre outros, tudo foi traçado pensando na melhoria da educação potiguar. O currículo e documentos oficiais da escola foram escritos pelas primeiras diretoras, sob a supervisão dos diretores da Liga de Ensino do Rio Grande do Norte. Neles estavam contidos os detalhes, as regras de convivência, os materiais que seriam usados, os cronogramas de estudos, o programa detalhado para os cursos a serem ofertados na escola, para cada ano, além das regras de admissão etc. Tudo foi planejado para que a educação feminina atendesse aos critérios de um ensino, voltados esses, para a formação da mulher, tornando-a apta para auxiliar a pátria na formação de cidadãos comprometidos com sua nação.

Além disso, anteriormente não era permitido que a mulher estudasse, só viram com bons olhos esse modelo educacional por que a motivação era que através da educação feminina, ou seja, o preparo de um currículo pautado em conceitos de educação do lar, música, artes, agricultura, puericultura, medicina, enfermagem [...], formariam uma mulher letrada e capaz de dar bons ensinamentos aos seus filhos, fazendo com que estes fossem úteis para a nação, e principalmente, cidadãos dedicados à pátria.

Entretanto, a mulher foi subestimada, acreditavam que ela ficaria limitada apenas a essas condições que lhes eram impostas ao serem inseridas no sistema educacional. Elas se tornaram promissoras, atuando não somente com primazia em suas casas, mas também exercendo um cargo público, foram professoras, enfermeiras, secretárias e posteriormente, médicas, engenheiras e etc.

Cada integrante da construção da escola contribuiu para moldar a cultura da escola, passou a desenvolver conjuntos de regras e práticas sociais dentro das pré-estabelecidas, permanecendo o que dava certo e reformulando as que causaram conflitos. O ensino com teoria e prática fazia parte da proposta da escola. As alunas tinham os laboratórios para praticar todo o ensino que lhes era ofertado.

De acordo com Miranda (2021, p. 68, no prelo),

O ensino da Puericultura veio para oportunizar uma educação que prevenia a mortalidade infantil que era tão debatida pela classe médica. A Escola Doméstica foi pioneira ao trazer o curso para o ambiente escolar, pois era visto apenas na formação médica, na Faculdade de Medicina do Rio de Janeiro, onde ocorreram as primeiras experiências dessa prática desse ensino, sob o comando do Dr. Arthur Moncorvo Filho, exímio pesquisador dos cuidados da infância, fundador do Instituto de Proteção e Assistência à Infância no Brasil. A Puericultura na Escola Doméstica promoveu técnicas adequadas de como cuidar de uma criança, abordando em seus aspectos naturais de desenvolvimento sem tratá-las como pequenos adultos. Ao implementar na instituição um ensino como o da Puericultura, a Escola Doméstica promoveu inovação em seu currículo.

Com professores qualificados, pôde contemplar a evolução no ensino de caráter inédito. As crianças carentes com idades de 0 até 6 passaram receber um atendimento adequado, apesar de ter sido modesto no começo, devido às condições financeiras, pois para tudo era necessário engajar projetos de arrecadação financeira, que muitas vezes foram realizados no palco do Theatro Carlos Gomes.

Era necessário que a sociedade entendesse a importância desse aprendizado, considerando essencial todo o percurso de construção de um ambiente adequado para os ensinamentos voltados para o cuidado da infância. Infelizmente era esperado que instintivamente as mulheres passassem a cuidar de seus filhos sem nenhuma noção, o que elas sabiam eram fruto da observação de suas mães, sendo perpassado de geração em geração.

O nosso questionamento nos deu direcionamento na busca de uma resposta sobre a contribuição da criação do Instituto de Puericultura para a formação científica e prática das alunas, nisto observamos os textos e relatos durante o estudo e percebemos os avanços no cuidado com a infância e a nova perspectiva que foi dada para a sociedade no tocante ao ensino do cuidado com a infância a partir da educação. A assistência à infância no Rio Grande do Norte, passou por uma evolução quando foi percebido o zelo com a prevenção das doenças causadoras da excessiva mortalidade infantil na região potiguar à época. O ensino da Puericultura na Escola Doméstica foi importante ao trazer conhecimento científico, por meio da teoria e prática 
necessárias à formação das alunas da época, usando-o para prevenção e promoção da saúde, ao mesmo tempo melhorando a qualidade de vida dos pequenos, a partir da instituição de novos centros de Puericultura, pois outras mulheres além das alunas também passaram a receber ensinamentos adequados, em anos posteriores ao da fundação do Instituto de Puericultura.

\section{Referências}

Arroyo, M. (1994). O significado da infância. In: Seminário Nacional de Educação Infantil. Brasília. Anais... [...]. Brasília: MEC/SE/COEDI, 1994.

Barras, V. (2001). Balexert, Jacques. In: Dicionário Histórico da Suíça (DHS). https://hls-dhs-dss.ch/fr/articles/019723/2001-12-27.

Barros, E. D. (2000). Uma escola Suíça nos trópicos. Natal, RN: Offset.

Bonilha, L. R. de C. M.(2004). Puericultura: olhares e discursos no tempo / Luís Roberto de Castro Martins Bonilha. Campinas, SP: [sn].

Bonilha, L. R. C. M \& Rivoredo, C. R. S. F (2005). Puericultura: duas concepções distintas. J. Pediatr. (Rio J.), Porto Alegre. 81 (1), 7-13. http://www.scielo.br/scielo.php?script=sci_arttext\&pid=S0021-75572005000100004\&lng=en\&nrm=iso.

Cascudo, L. da C. (2008). Nosso amigo Castriciano: 1874-1947: reminiscências e notas. Natal, RN: EDUFRN.

Certeau, M. de (1998). A invenção do cotidiano: artes de fazer. 3. ed. Petrópolis: Editora Vozes.

Fernandes, M. Z. (Org) (2016). Varela Santiago: visão de um homem. Natal: Instituto de Assistência e Proteção à Infância do RN.

Galvão, C. A. P. (2017). Um apóstolo entre nós. Natal, RN: Jovens Escribas.

Giordanengo, C. (2019). A dissertação sobre a educação física das crianças de Ballexserd. Hypotheses. Biblioteca Lyon Diderod.. https://bibulyon.hypotheses.org/12625.

Gondra, J (2000). A sementeira do porvir: higiene e infância no século XIX. Educação e Pesquisa, 26(1). 99-117. https://doi.org/10.1590/S1517-97022000000100008.

Julia, D. (2001). A cultura escolar como objeto historiográfico. Revista Brasileira de História da Educação. São Paulo, (1). 9-44. http://periodicos.uem.br/ojs/index.php/rbhe/issue/view/1392.

Le Goff, J, 1924 (1990). História e memória. Campinas. SP: Editora da UNICAMP. (Coleção Repertórios).

Lima, D. P. C. (2004). Noilde Ramalho: uma história de amor à educação. Natal: Liga de Ensino do Rio Grande do Norte.

Mendes, S. de L. \& Menezes, A. B. N. T.de. (2011). A história da educação infante natalense. Saberes: Revista interdisciplinar de Filosofia e Educação. (6). https://periodicos.ufrn.br/saberes/article/view/939.

Miranda, V.S. de (2021). A Escola Doméstica de Natal/RN e o Ensino da Puericultura no cuidado com a infância (1919-1929). Monografia (Graduação) Universidade Federal do Rio Grande do Norte, Centro de Educação, Pedagogia. Natal. (73). No prelo.

Nunes, M. F. R. \& Corsino, P. \& Didonet, V. (2011). Educação Infantil no Brasil: primeira etapa da educação básica. Brasília: UNESCO, Ministério da Educação, Secretaria de educação Básica, Fundação ORSA.

Perrot, M. (2007). Minha história das mulheres. São Paulo: Contexto.

Pinheiro, R. A. (2005). Educação e modernização em Henrique Castriciano. Natal, RN: EDUFRN.

Rizzini, I. \& Gondra, J. G. (2014). Higiene, tipologia da infância e institucionalização da criança pobre no Brasil (1875-1899). Revista Brasileira de Educação, 19 (58). 561-584

Rodrigues, A. G. F. (2007). Educar para o lar, educar para a vida: cultura escolar e modernidade educacional na Escola Doméstica de Natal. (1914 - 1945). Tese (Doutorado em Educação) Universidade Federal do Rio Grande do Norte, Centro de Ciências Sociais Aplicadas, Programa de Pós-Graduação em Educação. Natal, .

Santos, M. das G. de A. (Org.) (1998). A Escola Doméstica. 1 (1). Natal, RN: Escola Doméstica.

Saparolli, E. C. L. (2012). Puericultura. São Paulo: UNASUS; UNIFESP. Biblioteca Virtual. https://www.unasus.unifesp.br/ biblioteca_virtual/pab/1/unidades_casos_complexos/unidade12/unidade12_ft_puericultura.pdf.

Saviani, D. (2005). Instituições escolares: conceito, história, historiografia e práticas. Cadernos de História da Educação (4).

Silva, T. T. (2013). Documentos de identidade: uma introdução às teorias do currículo. (3). ed. Belo Horizonte: Autêntica. 